\title{
ENTREVISTA COM OS HISTORIADORES RENATO LEMOS E CLAUDIO BESERRA DE VASCONCELOS
}

\author{
Wagner Luiz Bueno dos Santos ${ }^{1}$ \\ Olivia Rocha Robba \\ Daniel de Almeida Dias ${ }^{3}$ \\ Jhonathan Ferreira da Matta
}

RESUMO: Nos últimos anos assistimos no Brasil um novo envolvimento dos militares na política nacional, que se acentuou após a última eleição presidencial (2018). A entrada de setores militares no governo, sobretudo os ligados ao alto comando das Forças Armadas, provocou um acalorado debate que tomou as páginas dos principais jornais de grande circulação do país, e este debate também é presente no ambiente acadêmico. Como se sabe, a participação dos militares em momentos decisivos da política brasileira não é uma novidade e, por isso, podemos estabelecer fios entre passado e presente. Para entendermos alguns aspectos que envolvem o universo militar, entrevistamos Renato

\footnotetext{
${ }^{1}$ Mestre em História Social pela Universidade Federal do Rio de Janeiro e Doutorando em História Social Universidade Federal do Estado do Rio de Janeiro. Pesquisador na Diretoria do Patrimônio Histórico e Documentação da Marinha. E-mail: wluizbueno@yahoo.com.br. Orcid: https://orcid.org/0000-0001-9092-9056.

${ }^{2}$ Especialista em Preservação e Gestão do Patrimônio Cultural das Ciências e da Saúde pela Fundação Oswaldo Cruz. Mestra em História das Ciências, das Técnicas e da Epistemologia pela Universidade Federal do Rio de Janeiro e Doutoranda em História Social pela Universidade de São Paulo. E-mail: oliviarobba@usp.br. Orcid: https://orcid.org/0000-0002-8322-8785.

${ }^{3}$ Graduando em História na Universidade Estadual do Rio de Janeiro. Bolsista na Diretoria do Patrimônio Histórico e Documentação da Marinha. E-mail: danieldiaslost23@gmail.com. Orcid: https://orcid.org/0000-0002-9070-3783.

${ }^{4}$ Graduando em História na Universidade Estadual do Rio de Janeiro. Bolsista na Diretoria do Patrimônio Histórico e Documentação da Marinha. E-mail: jhonathanferreira01@gmail.com. Orcid: https://orcid.org/0000-0003-4892-1637.
} 
Luís do Couto Neto e Lemos e Cláudio Beserra de Vasconcelos, historiadores que, além de traçarem uma análise sobre a história da participação dos militares na vida política brasileira, contam um pouco sobre suas trajetórias intelectuais.

PALAVRAS-CHAVE: Entrevista. Renato Lemos. Claudio Bessera de Vasconcelos. História militar.

\title{
INTERVIEW WITH THE HISTORIANS RENATO LEMOS AND CLÁUDIO BESERRA DE VASCONCELOS
}

\begin{abstract}
In Brazil, in recent years, we have seen a gradual involvement of the military in politics, a participation that was more evident after the last presidential election (2018). Military sectors, especially linked to the high command of the Armed Forces, when they joined the government, provoked a heated debate that took over the pages of the main newspapers of great circulation, it was no different in the academic environment. However, such participation is not new in national history, at decisive moments in Brazilian politics, the military has a prominent role acting as protagonists in the seizure of power and in the direction of the Brazilian State. To talk about this topic, we invited Renato Luís do Couto Neto e Lemos and Claudio Beserra de Vasconcelos, two historians who, in addition to drawing an analysis of the history of military participation in national political life, will tell us a little about their trajectories.
\end{abstract}

KEYWORDS: Interview. Renato Lemos. Claudio Bessera de Vasconcelos. Militar history.

\section{ENTREVISTAS CON LOS HISTORIADORES RENATO LEMOS Y CLAUDIO BESERRA DE VASCONCELOS}

RESUMEN: En Brasil, en los últimos años, hemos visto una participación gradual de los militares en la política, una participación que fue más evidente después de las últimas elecciones presidenciales (2018). Sectores militares, especialmente vinculados al alto mando de las Fuerzas Armadas, cuando ingresaron al gobierno, provocaron un acalorado debate que se apoderó de las páginas de los principales diarios de gran circulación y no fue diferente en el ámbito académico. Sin embargo, tal participación no es nueva en la historia nacional, una vez que en momentos decisivos de la política brasileña los militares tienen un papel destacado actuando como protagonistas en la toma del poder y en la dirección 
del Estado brasileño. Para hablar sobre este tema, invitamos Renato Luís do Couto Neto e Lemos e Claudio Beserra de Vasconcelos, dos historiadores que, además de hacer un análisis de la historia de la participación militar en la vida política nacional, nos contarán un poco sobre sus trayectorias intelectuales.

PALABRAS CLAVE: Entrevista. Renato Lemos. Claudio Bessera de Vasconcelos. Historia militar.

\section{PRIMEIRA PARTE: ENTREVISTA COM RENATO LUÍS DO COUTO NETO E LEMOS}

Entrevistadores: Professor Renato Lemos, primeiramente, gostaríamos de agradecê-lo por nos conceder essa entrevista. Para começarmos, você poderia nos contar um pouco sobre sua trajetória acadêmica?

Renato Lemos: Agradeço o convite e é um prazer poder contribuir com essa iniciativa. Eu cursei História na Universidade Federal Fluminense (UFF) de 1971 a 1976. Era, como se vê, um momento de grande dificuldade para a vida acadêmica, por conta do regime ditatorial em que vivíamos, mas havia certo grau de liberdade na UFF, muito menos visada do que universidades como as de São Paulo (USP), Brasília (UnB) e Federal do Rio de Janeiro (UFRJ).

Entrevistadores: Ainda sobre sua trajetória, como foi o seu processo de inserção no mundo acadêmico e como tem sido sua vida como professor universitário em sua área de pesquisa?

Renato Lemos: Quando entrei na vida acadêmica já tinha uma visão de mundo definida, basicamente, pela militância como estudante secundarista em uma organização clandestina de oposição ao regime ditatorial então vigente. Nos grupos de estudos que formávamos na organização, eu entrava em contato com os temas de história nacional e mundial que marcavam os debates políticos da época. Quando iniciei a graduação, já conhecia boa parte da bibliografia mobilizada nas disciplinas. Mas é claro que a universidade me propiciou conhecer os aspectos acadêmico e profissional da área de História, aliás, bem diversos dos atuais. 
Entrevistadores: Ao longo de sua trajetória, quais os principais temas e problemas que você se dedicou a estudar? Mais especificamente, quais suas contribuições teóricas e metodológicas para os estudos sobre os militares no Brasil?

Renato Lemos: Tive algumas experiências, ainda como graduando, como assistente de pesquisa de professores. Na época, praticamente inexistiam bolsas de iniciação científica. $\mathrm{Na}$ UFF, os professores de História começavam, em sua maioria, a se pós-graduar e pagavam, dos seus salários, alunos para os auxiliarem na pesquisa para dissertações e teses. Meu primeiro emprego na área foi no Centro de Pesquisa e Documentação em História do Brasil Contemporâneo (CPDOC) da Fundação Getúlio Vargas. Fui admitido em 1979 como pesquisador no projeto do Dicionário Histórico-Biográfico Brasileiro (DHBB). Produzi dezenas de verbetes sobre personagens da nossa história política pós-1930 e adquiri conhecimentos factuais e metodológicos na zona de interseção biografia/ história que contribuiriam decisivamente para as minhas perspectivas enquanto pesquisador.

Concluído o DHBB em 1983, passei a integrar uma equipe formada para desenvolver o projeto de História Política do Estado do Rio de Janeiro. Coube-me, especificamente, pesquisar a história política fluminense nas conjunturas históricas de transição da Monarquia para a República e de consolidação da nova ordem na primeira década republicana. A pesquisa resultou em três capítulos da obra coletiva $A$ República na Velha Província, publicada em 1989. As partes de minha autoria incorporam resultados da minha dissertação de mestrado - A implantação da ordem republicana do estado do Rio de Janeiro (1889-1892) -, que defendi na UFF em 1985.

Em 1987, aceitei um convite para dirigir o Centro de Pesquisas de História da República do Museu da República, subordinado ao Ministério da Cultura. Lá atuei por dois anos, tendo, também, dirigido a Divisão de Documentação e Pesquisa, que incluía o Centro, o Arquivo Histórico e a Biblioteca do Museu. Era um período totalmente subordinado aos objetivos de reabrir o Museu, fechado durante alguns anos para restauração do prédio, e prepará-lo para as comemorações do centenário da República. Absorvido pelas tarefas administrativas, pouco fiz na área acadêmica. 
Em 1989, ingressei no doutorado em história da UFF, com um projeto de tese voltado para o estudo do conservadorismo político fluminense. No fim do ano, fui transferido para o Museu Casa de Benjamin Constant (MCBC), para atuar somente como pesquisador. No segundo ano do doutorado, precisei trancar o curso. $\mathrm{O}$ trabalho com o arquivo pessoal de Benjamin Constant acabou me induzindo a abandonar o meu projeto original e, tendo retomado o doutorado, passei a me dedicar à biografia do patrono do MCBC.

Por razões financeiras - o Ministério da Cultura não dispunha de um quadro de carreira que valorizasse a condição acadêmica - e intelectuais desejo de me forçar a estudos com escopo mais variado do que a pesquisa especializada me exigia -, projetei ingressar na área universitária como professor. Em dezembro de 1996 me demiti do serviço público. No mês seguinte, defendi a tese Benjamin Constant - vida e história, publicada com o mesmo título em 1999, simultaneamente a Cartas da Guerra - Benjamin Constant na Campanha do Paraguai, coletânea de exemplares remanescentes da sua correspondência, por mim transcrita e comentada.

Depois de um ano e meio trabalhando para o CPDOC-FGV como colaborador externo na atualização do $D H B B$, quando fiquei responsável por alguns dos verbetes mais importantes, prestei concurso para o Departamento de História (atual Instituto de História) da Universidade Federal do Rio de Janeiro. Aprovado, iniciei a minha trajetória como professor em junho de 1998. Como se sabe, os encargos de professor nas universidades federais de grande porte incluem atuar na graduação e na pós-graduação e é isso que tenho feito nesses 22 anos. As atividades de minha livre orientação, em termos de pesquisa e aulas, têm se estruturado, basicamente, em torno de temas ligados à história da relação entre militares e política no Brasil - tema para o qual despertei quando trabalhava no MCBC, com o acervo do general Pery Constant Bevilaqua, sobre o qual publiquei vários trabalhos - e à história do regime ditatorial instalado no país a partir do golpe que depôs o presidente João Goulart em 1964. Neste sentido, tenho oferecido cursos na graduação e na pós-graduação. Há cerca de 20 anos ministro o curso "Ditadura militar - história e historiografia", que reputo muito importante no quadro historiográfico respectivo, porque nele deba- 
to com os alunos de pós-graduação textos de importantes autores pouco considerados pelas correntes hegemônicas na área, como Florestan Fernandes, René Armand Dreifuss e Guillermo O’Donnell.

Em outra esfera, venho, desde o meu ingresso na UFRJ, oferecendo a alunos de todos os níveis e, mesmo, de outras instituições, o Laboratório de Estudos sobre os Militares na Política (LEMP). Tenho organizado programas de estudos que combinam temas históricos com questões contemporâneas relativas à presença dos membros das Forças Armadas no cenário político. Tenho a permanente preocupação metodológica com a abordagem a adotar em relação ao tema. Critico as teses consagradas, principalmente a liberal e a conservadora, e procuro avançar na perspectiva marxista, que situa as relações entre militares e processos políticos a partir da visão classista do Estado, instância da sociedade em que se estruturam as Forças Armadas. O LEMP publicou a revista eletrônica Militares e Política e foi, durante dez anos a partir de 2005, a base de simpósios temáticos organizados nas reuniões nacionais e regionais da Associação Nacional de História (ANPUH). Da convergência entre as atividades do LEMP e na graduação e na pós-graduação, têm surgido monografias, dissertações e teses que fazem avançar o conhecimento na área temática. Exemplos de teses originadas nessa convergência e publicadas são as de Fabiano Godinho Faria, Os militares e a crise de 1964 (2014), e de Cláudio Beserra de Vasconcelos, Repressão a militares na ditadura pós-1964 (2018).

Desde o cinquentenário do golpe de 1964, venho diversificando as minhas atividades de pesquisa nos campos temáticos do processo político durante a ditadura. Nesse sentido, publiquei em 2018 o livro Ditadura, anistia e transição política, no qual analiso a relação da ditadura com a formação de um complexo industrial militar e a configuração do anticomunismo empresarial-militar no Brasil, temas sobre os quais tenho publicado capítulos em obras coletivas. No momento, aguardo o lançamento do livro Empresários e ditadura no Brasil, coletânea que organizei com dois companheiros do Grupo de Trabalho empresariado e ditadura.

Entrevistadores: Nos últimos anos têm se discutido muito a importância da divulgação do conhecimento científico para públicos mais 
amplos. No caso da História Militar, como podemos construir diálogos que ajudem a tornar mais público personagens e elementos centrais da história dos militares no Brasil?

Renato Lemos: Bem, antes de tudo, preciso esclarecer que não trabalho com "história militar" em sentido estrito - batalhas, organização, armamentos etc. -, mas com a história das relações dos militares com a política. Mas entendo que os problemas sejam os mesmos. É o problema da aproximação da vida acadêmica com o cotidiano da população. As atividades ditas de extensão parecem ser o melhor caminho para isso no âmbito da universidade. Mas entidades civis, como a ANPUH e a ABED (Associação Brasileira de Estudos de Defesa), também podem cumprir um papel importante no sentido de disseminar mais amplamente as questões e o conhecimento relativos à área temática.

Entrevistadores: Você poderia aprofundar um pouco qual tem sido sua relação com as fontes de pesquisa? Olhando em perspectiva para o conjunto de seus trabalhos, você encontrou dificuldades para acessar materiais específicos? Perguntamos isso porque, apesar da lei de acesso à informação brasileira, alguns pesquisadores que estudam a História Militar relatam dificuldades de acessar certos arquivos e documentos. Isso já ocorreu com você ou com seus orientandos?

Renato Lemos: Sim, os estudos que envolvam arquivos privados - individuais ou coletivos - e públicos relativos a militares ou instituições castrenses, geralmente, enfrentam problemas de acesso. Às vezes, na forma de dificuldades administrativas, outras vezes, de tipo restritivo mesmo, próximo à censura. Pesquisas sobre a participação de militares no regime ditatorial, por exemplo, frequentemente se deparam com a informação da inexistência de um determinado acervo documental de que se tem registro em códices levantados na fase de levantamento de fontes.

Entrevistadores: A História dos Militares está inserida, em geral, na história da formação dos Estados Nacionais. No caso brasileiro, em que medida a história dos militares compõe a narrativa histórica do Estado Nacional? É possível pensar a construção da política atual a partir da História dos Militares? 
Renato Lemos: Na história de várias formações sociais, as forças armadas tiveram papel fundamental na formação dos Estados nacionais. Em algumas situações, até mesmo antecederam, ou melhor, atuaram na construção desse tipo de Estado, como nos casos da Rússia, Portugal e Espanha. O caso do Brasil guarda alguma semelhança, apesar da singularidade de ter sido uma colônia. Como a transição para o Estado independente se fez sem maiores rupturas com a Metrópole, as Forças Armadas - Exército e Marinha -, cuja organização foi mantida, de alguma forma antecederam o Estado Nacional. Mas eu penso que a história das Forças Armadas não pode ser tomada como um fio condutor para o conjunto da nossa história política. Já nos quadros da República, sim. Não só por se tratar de uma forma política cuja existência histórica se deve, em grande parte, à ação de segmentos militares, mas porque temos vivido um processo de construção e crise de regimes políticos em que as Forças Armadas têm sido um elemento central (...)

Entrevistadores: É possível notar que alguns dos pilares fundamentais para a construção de visões políticas que modulam o debate contemporâneo são o resgate de valores conservadores e os usos políticos da memória, principalmente as relacionadas ao poder político exercido pelos militares após o golpe de 1964. É possível sugerir que os valores conservadores e autoritários fazem parte do conjunto da sociedade brasileira? Como relacionar essa questão com os chamados de alguns setores sociais pela intervenção militar em momentos de crise, como ocorreu em 1964 e, recentemente, nas manifestações populares que tomaram as ruas no decorrer dos últimos anos?

Renato Lemos: Não seria exagero dizer que a participação dos militares em posição protagonista constitui um traço da longa duração da formação social brasileira. E isto intriga os analistas da política brasileira contemporânea. Do meu ponto de vista, a presença maciça de militares, atualmente, em várias instâncias governativas da nossa sociedade é produto do cruzamento de duas tendências. Uma, de médio prazo, é o processo de militarização dos Estados capitalistas a partir do fim da Segunda Guerra Mundial, acentuado dramaticamente pelo chamado "Atentado às 
Torres Gêmeas", nos Estados Unidos, em 2001. Outra, de curto prazo, é a crise do regime político democrático instituído pela Constituição de 1988. A participação militar em episódios cruciais como a destituição da Monarquia em 1889, a deflagração do golpe do Estado Novo em 1937 e a deposição do presidente João Goulart em 1964 se explicam, em grande parte, pela percepção castrense de que a ordem sócio-política se encontrava ameaçada por algum fator que poderia ser anulado pela intervenção militar. Esta perspectiva está presente na atual conjuntura, ainda que os principais argumentos para a intervenção estejam muito colados na situação contemporânea. Mesmo assim, o campo militarista maneja argumentos de longa duração, como a desqualificação da política e dos políticos em confronto com uma suposta superioridade moral e técnica dos militares, argumento tão antigo quanto a Guerra do Paraguai.

Entrevistadores: $\mathrm{Na}$ sua perspectiva, quais são as referências incontornáveis para compreender a História dos Militares no Brasil? Quais sugestões você daria para alguém que está iniciando os estudos sobre esta temática ou mesmo para um público mais amplo que tenha interesse em conhecer o papel dos militares e dos militarismos no país?

Renato Lemos: A historiografia brasileira apresenta muitos e diversificados trabalhos sobre a história da relação entre os militares e a política. Mas nem todas as obras têm este tema como central em suas pesquisas. Às vezes os militares surgem na dinâmica da conjuntura, outras vezes como elemento do sistema político. No meu campo de estudos, há trabalhos importantes por seu pioneirismo em termos de abordagem e outros, pelas propostas de análise e resultados obtidos. Uma lista referente apenas a autores fundamentais para a compreensão dos paradigmas analíticos disponíveis no campo historiográfico militares-política destacaria obras de Alan Rouquié, Alfred Stepan, Edmundo Campos Coelho, José Murilo de Carvalho e Nelson Werneck Sodré. 


\section{SEGUNDA PARTE: ENTREVISTA COM CLAUDIO BESERRA DE VASCONCELOS}

Entrevistadores: Professor Claudio Beserra, primeiramente, gostaríamos de agradecê-lo por nos conceder essa entrevista. Para começar, você poderia nos contar um pouco sobre sua trajetória acadêmica?

Claudio Beserra: Sou graduado, mestre e doutor em História pela Universidade Federal do Rio de Janeiro. Acho que posso dizer que desde criança temas ligados à política me atraíam. Não entendia o que estava acontecendo, mas assistia aos telejornais e as reportagens sobre política me chamavam a atenção. Vivi a adolescência na virada da ditadura para o regime democrático, e a fase pessoal de contestação, em um contexto político nacional de ebulição política, tendo como trilha sonora a explosão do rock nacional e suas letras críticas, se somavam. Apesar de tudo isso, não pensava, inicialmente, em cursar História. Somente, com o tempo, consolidei essa opção de carreira.

Quando ingressei na faculdade, em 1994, queria estudar a ditadura, mas não sabia exatamente o quê e nem como. Já mais para o fim do curso é que conheci o professor Renato Lemos, recém-ingresso na universidade. Conversamos, apresentei minhas ideias, e ele me apontou caminhos. Firmamos, então, uma parceria/orientação que levou à minha monografia de fim de curso, e se estendeu ao mestrado, no qual ingressei em 2002, e doutorado, iniciado em 2006, e, em grande medida, permanece até hoje. Antes disso, o professor Renato criou o Laboratório de Estudos sobre os Militares na Política (LEMP) e me convidou para participar. Com o tempo, fui conhecendo melhor e me interessando mais pela questão. Assim, acabei desenvolvendo pesquisas que têm como pano de fundo a ditadura, mas que procuram analisar mais especificamente a atuação dos militares na política.

Com relação ao desenvolvimento acadêmico de minhas pesquisas, em um primeiro momento, me dediquei a conhecer as diversas interpretações sobre a participação dos militares na política. Firmei a perspectiva de que os militares são mais um ator dentro do cenário político, possuem características próprias, mas suas ações refletem interações com o meio 
sócio-político mais geral e têm orientação classista. A partir desse ponto de vista, desenvolvi pesquisas que buscam entender o regime ditatorial como tendo caráter empresarial-militar, sendo os militares um elemento central de uma unidade de frações de classe em disputa pela tomada do poder e pela direção do país.

Especificamente, na monografia de final de curso de graduação, ative-me à história política do período compreendido entre a renúncia de Jânio Quadros e a deposição de João Goulart, e, tendo por base os editoriais do Diário de Notícias, discuti como este jornal viu a participação política dos militares, o que poderia estar por trás de tais discursos e até que ponto a sanção civil foi essencial para a deflagração e para o sucesso da intervenção militar. Na dissertação de mestrado, analisei o problema da legitimidade no regime empresarial-militar brasileiro entre 1964 e 1968, com ênfase na preservação de instituições democráticas. Parti do pressuposto de que qualquer regime político, seja ele democrático ou autoritário, necessita construir bases de legitimidade para o estabelecimento e preservação do seu projeto de dominação. Desse modo, teria que buscar o consentimento de parcelas significativas da sociedade. No caso brasileiro, a ditadura teria procurado aceitação junto às camadas médias e alta da sociedade. Sustentando a tese de que a democracia era a formação discursiva dominante no imaginário político e social do Brasil dos anos 1960, defendi a hipótese de que, para legitimar-se, o regime teria optado por preservar princípios e instituições típicos das democracias-liberais. Entre os quais, o Poder Legislativo em funcionamento e em "diálogo" com o Executivo. Já no doutorado, analisei a política repressiva aplicada aos militares entre o golpe de 31 de março de 1964 e o início do ano de 1970, com ênfase no processo de disputa político-ideológica pelo controle do Estado brasileiro, intensificado a partir de 1945. Sustentei a hipótese de que a partir de fins dos anos 1940 gestou-se um projeto de desenvolvimento capitalista cuja intenção era integrar o Brasil de forma dependente à estrutura do capitalismo internacional, o que implicava na superação de entraves políticos, econômicos e sociais, e levou à necessidade de conquista, controle e reformulação do Estado brasileiro. Como um dos meios para o estabelecimento deste projeto, admitia-se o recurso à prática da repressão 
política, inclusive de militares, por terem eles participado de maneira central do debate sobre o tipo de desenvolvimento adequado para o Brasil e acabado divididos. Assim, após o golpe, os militares que defenderam de forma ativa uma proposta nacionalista desde o final da década de 1940 se tornaram um dos alvos privilegiados do processo repressivo.

Entrevistadores: Ainda sobre sua trajetória, como foi o seu processo de inserção no mundo acadêmico e como tem sido sua vida como pesquisador e professor universitário?

Claudio Beserra: A universidade transforma as pessoas. Talvez seja a experiência mais diversa e rica que eu tenha vivido. Estudar em uma universidade pública tendo contato com alunos e professores de realidades totalmente diversas à minha me transformaram profundamente, ampliando muito a percepção sobre o mundo.

Com relação à minha trajetória no mundo acadêmico como docente, ela é curta. Estive como professor substituto no Instituto de História e Relações Internacionais da Universidade Federal Rural do Rio de Janeiro durante três semestres entre 2016 e 2017, ministrando as disciplinas: Formação Histórica do Brasil II (Brasil República: 1889dias atuais); História do Brasil IV (Brasil República: 1930-dias atuais); História da América III (século XX-XXI); Ditadura Militar Brasileira: história e historiografia. Novamente, foi uma experiência riquíssima e transformadora. Pude travar contato com estudantes dos cursos de História, Relações Internacionais e Ciências Sociais e perceber as carências deles e as minhas e, a partir delas, aprofundar estudos no sentido de sanálas. Aprendi demais em muito pouco tempo.

Além da trajetória como professor, procuro me manter ativo em grupos de pesquisa, em congressos e como pesquisador, escrevendo livros e artigos e publicado em revistas científicas e capítulos de livros. Minha tese de doutorado foi uma das vencedoras do Prêmio de Pesquisa Memórias Reveladas, edição 2014, promovido pelo Arquivo Nacional. Como resultado, ela foi publicada em livro com o título Repressão a militares na ditadura pós-1964, no ano de 2018. Dessa pesquisa também resultaram os artigos: "A política repressiva contra militares no Brasil após o golpe 
de 1964", publicado na revista Locus, da Universidade Federal de Juiz de Fora, em seu volume 12, no ano de 2006; "A repressão política aos cabos da Força Aérea Brasileira após o golpe de 1964", na revista Tempos Históricos, volume 23, ano 2019; e "A Escola Superior de Guerra e as raízes da repressão política aplicada a militares após o golpe de 1964", na revista Antíteses, no volume 13, editado em 2020. Relacionados à minha pesquisa de mestrado, publiquei: "Os militares e a legitimidade do regime ditatorial (1964-1968): a preservação do Legislativo”, pela revista Varia História, da Universidade Federal de Minas Gerais, volume 29, em 2013; e "O discurso da democracia: imprensa e hegemonia da ditadura empresarial-militar brasileira (1964-1968)", na revista Tempo e Argumento, em seu volume 11, no ano de 2019. De modo geral, esses trabalhos dialogam com a perspectiva mais geral que adoto sobre o tema, já mencionada anteriormente: a de que as ações militares têm orientação classista.

Sem estar diretamente relacionado a essas duas pesquisas de maior fôlego, produzi o artigo "As análises da memória militar sobre a ditadura: balanço e possibilidades", publicado na revista Estudos Históricos, da Fundação Getúlio Vargas, no volume 22, do ano de 2009, no qual procuro debater os cuidados que devemos ter ao tomarmos as memórias de militares como meio de compreensão das razões que levaram ao golpe de 1964.

Entrevistadores: Ao longo de sua trajetória, quais os principais temas e problemas que você tem se dedicado? Mais especificamente, quais suas contribuições teóricas e metodológicas para os estudos sobre os militares no Brasil?

Claudio Beserra: Tendo a atuação militar como elemento unificador, eu trabalhei com temas que abordavam o papel da imprensa, do poder legislativo, a repressão política e a memória construída sobre a ditadura. Em termos teórico-metodológicos mais gerais, procuro contribuir para o debate sobre a caracterização do regime, destacando o seu caráter de classe empresarial-militar.

Nesse sentido, trabalhando fundamentalmente com arquivos das Polícias Políticas e com processos abertos contra militares no Superior 
Tribunal Militar (STM), minhas pesquisas buscam perceber o golpe como o ápice de um processo de disputa pelo controle do Estado brasileiro. Ao contrário de certas correntes historiográficas que tendem a buscar as motivações da tomada de poder na crise política dos anos 1961-1964, creio que esse embate se desenvolve durante um período maior. Entendo que as raízes se encontram no pós-Segunda Guerra, ganham corpo durante os anos 1950 e têm o início dos anos 1960 como clímax. Em paralelo, dialogo com as perspectivas historiográficas que têm procurado destacar a participação civil no golpe e na ditadura. Me distancio do grupo que tende a perceber uma associação mais geral, homogênea da "sociedade brasileira" ao golpe e à ditadura, e me aproximo dos trabalhos de Renato Luís do Couto Neto e Lemos, Pedro Henrique Pedreira Campos, Martina Spohr Gonçalves, Elaine de Almeida Bortone, Rejane Carolina Hoeveler e Rafael Vaz da Motta Brandão, entre outros, além do clássico trabalho de René Armand Dreifuss, que destacam de modo mais específico os grupos sociais que tiveram esse comportamento: o elemento empresarial. Dada a percepção da complexidade dos grupos em disputa, procuro contribuir com esse debate demonstrando que, se do lado vencedor não havia só militares, mas também civis, do lado derrotado não havia só civis, mas muitos militares, homens que defendiam um modelo de desenvolvimento para o Brasil distinto do adotado a partir da ditadura e que, essencialmente por isso, compuseram o grupo de funcionários públicos percentualmente mais cassado após o golpe de 1964.

Entrevistadores: Nos últimos anos têm se discutido muito a importância da divulgação do conhecimento científico para públicos mais amplos. No caso da História Militar, como podemos construir diálogos que ajudem a tornar mais público personagens e elementos centrais da história dos militares no Brasil?

Claudio Beserra: Entendo que a divulgação da História, de forma geral, deve seguir da mesma forma: congressos, publicações de livros, artigos, enfim, de pesquisa científica. Em um segundo momento, é preciso buscar meios de levar os resultados dessa produção ao um público mais geral, seja através de inserção no material didático para uso em escolas 
seja pela produção de material multimídia, para divulgação nos eletrônicos mais populares.

No que se refere especificamente à História Militar, entretanto, entendo que alguns rumos precisam ser revistos. Creio que a visão coletiva e, em parte, da própria historiografia sobre a História Militar no Brasil, ainda tende a percebê-la ou valorizá-la pelo seu aspecto mais puramente institucional. No que se refere à autoprodução militar, ela é centrada em grandes feitos e personagens da história. A própria instituição, em suas celebrações, procura reforçar este aspecto memorialístico e laudatório. Nesse sentido, creio que a produção acadêmica e sua posterior publicização deve procurar desconstruir mitos e, sempre, buscar inserir a "história militar" e de militares em um contexto mais amplo do período. Militares e a instituição militar não estão alheios aos demais corpos sociais e, tampouco, são portadores de virtudes únicas e incontestáveis. Sua história é constituinte da história mais geral do país e sofre os efeitos dos contextos específicos. Creio, pois, que é na interação entre o que é mais específico da instituição e o que é mais geral que a atuação dos militares na política deve ser percebida e, em seguida, popularizada.

Entrevistadores: Você poderia aprofundar um pouco qual tem sido sua relação com as fontes de pesquisa? Olhando em perspectiva para o conjunto de seus trabalhos, você encontrou dificuldades para acessar materiais específicos? Perguntamos isso porque, apesar da lei de acesso à informação brasileira, alguns pesquisadores que estudam a História Militar relatam dificuldades de acessar certos arquivos e documentos. Isso já ocorreu com você ou com seus orientandos?

Claudio Beserra: Para quem estuda militares no período da ditadura, a questão do acesso às fontes é sempre um pouco complexa. Muitas vezes temos que buscar fontes de forma "indireta", em fundos não necessariamente militares, mas que nos forneçam as informações que procuramos. Ao agir dessa forma, consegui um bom material, mas também obtive acesso a fontes diretamente em instituições militares, especialmente aquelas constantes de boletins e publicações de caráter administrativo e ordinário. Algumas vezes, de maneira simples, sem 
qualquer questionamento ou exigência, mas, em outras, passei por "entrevistas" e tive que apresentar longas justificativas e ponderações para conseguir a liberação. Especificamente, isso ocorreu no Arquivo Histórico do Exército (AHEX) e no Arquivo da Marinha. Eu buscava por dados funcionais de militares (promoções, possíveis punições, passagem para reserva, falecimento) e, no AHEX, foi permitido acesso direto à documentação, mas, no caso da Marinha, eu listei o que queria e a pesquisa foi feita por um funcionário do próprio arquivo. Contudo, também fiquei sem resposta quando tentei pesquisar processos que estão depositados no Superior Tribunal Militar (STM). Mandei um e-mail e nunca recebi qualquer retorno. Neste caso, não insisti ou busquei acesso via lei de acesso a informações, pois consegui pesquisar o que queria através de fundos depositados em outras instituições.

Entrevistadores: Em relação aos usos políticos da História, é possível pensar a construção da política atual a partir da História dos Militares? Em que medida a historiografia, que se volta para os estudos sobre o passado, pode contribuir para refletir sobre elementos do tempo presente?

Claudio Beserra: Em qualquer tempo, o militar foi ator político importante. No que se refere à história da República brasileira, que é o campo em que insiro minhas pesquisas e estou mais apto a responder, entendo que sim, é possível pensar a construção da política atual a partir da História dos Militares. Nossa república nasce, se desenvolve, se transforma, se desconstrói e reconstrói mediante a ação e/ou sobre a sombra da ação militar. Pensar a realidade atual sem estabelecer correlações com o papel sócio-político representado pelos militares seria insuficiente.

Como bem disse Marc Bloch, "A incompreensão do presente nasce fatalmente da ignorância do passado". Cabe, pois, aos historiadores, com olhos postos no presente, compreender o nosso passado e mantê-lo vivo. É preciso, portanto, refletir sobre os caminhos e carências de nossa República na atualidade e, dada a presença central dos militares em sua constituição, da gênese aos nossos dias, analisar a sua participação, suas vinculações de classe e suas responsabilidades sobre os rumos do nosso país. É imperioso, no entanto, buscar compreender melhor o elemento 
militar. Apesar de todo o processo interacional, a percepção castrense da dinâmica sócio-política e a sensibilidade com relação a aspectos da geopolítica têm suas particularidades. Além disso, há também interesses próprios, organizacionais, que não podem passar despercebidos de qualquer análise que os englobe.

Entrevistadores: A História dos Militares está inserida, em geral, na história da formação dos Estados Nacionais. No caso brasileiro, em que medida a história dos militares compõe a narrativa histórica do Estado Nacional?

Claudio Beserra: A partir da perspectiva de que a construção do Estado Nacional é um processo que segue até os nossos dias, e reproduzindo argumento da resposta à questão anterior, a evolução do Estado Nacional brasileiro, da nossa sociedade, da nossa política, da nossa realidade são absolutamente indissociáveis da história dos militares.

Entendo que as disputas giram em torno do papel que cabe aos militares na liderança dos processos políticos e sociais, especialmente os republicanos. Trata-se de uma disputa de narrativas. Historicamente, os militares advogam para si um caráter de instituição moldada em virtudes e que, como tal, caberia a eles um papel de principais, quando não únicos, protetores do regime político. Seriam, por essa perspectiva, soldadoscidadãos mais capazes de executar tal função. Em outros termos, além de construtores e consolidadores do Estado Nacional, seriam também salvadores da pátria e detentores de qualidades que os habilitariam a intervir e atuar, direta ou indiretamente, em qualquer domínio da vida social. Esse papel de guardiões da sociedade e a ideia de virtude imanente aos militares precisam ser problematizados. Para que possamos construir um país em que a "coisa pública" seja, de fato, de todos, os contextos sócio-políticos em que tais discursos, sempre vivos, foram moldados e ganham audiência precisam ser considerados, as interações e relações classistas dos militares têm de ser desnudadas.

Sobre outras nações, é inegável a presença central dos militares na história de diversos países latino-americanos e na constituição de seus Estados Nacionais. Além disso, mesmo naqueles em que não houve 
por tradição a existência de governos militares, é possível perceber a centralidade militar, como é o caso do recurso à instituição como instrumento de política externa. Uma primeira forma dessa atuação se refere à defesa interna e influência política direta, através da demonstração de força, como é o caso dos Estados Unidos e seu hard power, ou seja, seu poderio militar incontestável que lhe dá uma capacidade inigualável de coerção e que é usado com frequência - vide as intervenções militares norte-americanas - em detrimento do recurso à diplomacia para resolução de questões internacionais. Um segundo meio de atuação militar como instrumento de política externa se refere a termos indiretos, econômicos, vistos os valores e a ascendência envolvidos no comércio de armas e tecnologia de uso militar. Exemplar desse caráter é o caso da disputa diplomática entre França e os Estados Unidos para a venda de caças ao governo brasileiro, nos anos 1970. O papel desempenhado por Pierre Lallart, e Paul Aussaresses, adidos militares franceses no Brasil entre 1962 e 1964 e 1973 e 1975, respectivamente, são centrais para que a escolha se desse pela proposta francesa. Veteranos das guerras da Indochina e da Argélia e especialistas em guerra revolucionária, Lallart e Aussaresses irão difundir essa doutrina a militares brasileiros, muitos deles já formados sob a influência da Missão Militar Francesa (1920-1940). Lallart vislumbrou, com a ditadura brasileira, uma oportunidade da França recuperar, no Brasil, sua influência militar perdida para os americanos no pós-Segunda Guerra, e obteve sucesso nas negociações preliminares da venda de aviões Mirage ao Brasil. Aussaresses, por sua vez, esmerou-se na construção de uma rede de relações com militares brasileiros, especialmente os encarregados das compras das Forças Armadas. Essa aproximação incluía a exportação de técnicas militares francesas para combate aos ditos subversivos internos e se mostrou fundamental para que o Brasil incrementasse a compra de armamento francês, de modo geral, e optasse, por fim, pela aquisição de caças Mirage.

Entrevistadores: É possível notar que alguns dos pilares fundamentais para a construção de visões políticas que modulam o debate contemporâneo são o resgate de valores conservadores e os usos políticos 
da memória, principalmente as relacionadas ao poder político exercido pelos militares após o golpe de 1964. Considerando o atual revisionismo histórico sobre aquele período, como você analisa o papel da memória do regime militar?

Claudio Beserra: Entendo que a questão da memória sobre a ditadura é elemento central do revisionismo historiográfico sobre o período e fomenta a difusão de valores conservadores. Embora o início desse revisionismo date da virada dos anos 1980 para os 1990, foi nos anos 2000 , tendo a questão da memória sobre a ditadura como eixo, que esse debate foi intensificado e ganhou as páginas dos jornais. A assunção das perspectivas presentes na memória militar como respostas e justificativas suficientes para explicar a tomada do poder em 1964, sem que fosse feita uma adequada correlação com o contexto sócio-político e sem a percepção de suas relações de classe, resultou em um ocultamento da história, em um entendimento parcial, quando não equivocado da realidade vivida. A publicização desses argumentos deu novo ânimo à histórica percepção militar de salvadores da pátria, e possibilitou a reconstrução da memória coletiva em torno da ditadura. Em um momento de crise política, migrar dessa memória à defesa da intervenção militar como solução para os problemas do país não foi muito custoso.

Com relação a um possível revisionismo historiográfico sobre as ditaduras latino-americanas, eu não tenho elementos para afirmar se existe ou não. Há, contudo, na Argentina ao menos, a partir do governo de Maurício Macri, o crescimento da ênfase na teoria dos "dois demônios", do discurso de que houve uma "guerra suja" em que os dois lados cometeram excessos, tese incompatível com a realidade vivida naquele país, mas que ganha espaço no debate público, e serve de adubo para teorias que buscam tornar positiva a amarga experiência vivida em tempos de ditadura e, como tal, a valorizar a atuação dos militares.

Entrevistadores: Aprofundando a questão anterior, é possível sugerir que os valores conservadores e autoritários fazem parte do conjunto da sociedade brasileira? E como relacionar essa questão com os chamados de alguns setores sociais pela intervenção militar em momentos de crise, 
como ocorreu em 1964 e, recentemente, nas manifestações populares que tomaram as ruas no decorrer dos últimos anos?

Claudio Beserra: Valores conservadores fazem parte de qualquer sociedade. Dependendo do país e do contexto, eles podem estar mais vivos ou não. O Brasil não é diferente. Até que ponto, em quais contextos, sobre quais questões somos mais ou menos conservadores que outras sociedades, é difícil avaliar. Em todo caso, há uma relação entre a defesa de valores conservadores e os chamados pela intervenção militar. Por excelência, as instituições militares trabalham pela conservação da ordem existente, defendem, pois, tais valores. Logo, grupos que defendem ideais conservadores e/ou culpam uma suposta desordem sócio-política pela crise vivida encontrarão na instituição militar um modelo a ser exaltado, como se fosse a solução de seus problemas. Essa percepção, contudo, tem relação direta com a questão da revisão da memória em torno do regime, como exposto na resposta à questão anterior. Se não tivesse sido resgatada e revalorizada a tese dos militares como "salvadores da pátria", a simpatia por ideias conservadoras não levaria à defesa de uma intervenção militar como solução para os nossos problemas.

Com relação à comparação entre os dois períodos (1964 e atualidade), são contextos distintos. Qualquer comparação exige cuidados. No entanto, podemos dizer, de forma simplista, que setores da elite econômica e parte da classe média, temerosa da redução de seu poder aquisitivo, do seu padrão de vida, compõe a fração social que apoiou os dois momentos. Os chamados por uma intervenção representam, para os militares, a possibilidade de retornarem ao primeiro plano da cena política. Embora nunca tenha abandonado esse palco após o fim da ditadura, os militares não eram exatamente os protagonistas, os condutores primazes dos rumos do país. Uma intervenção, calcada na tese do soldado-cidadão, redentor das virtudes republicanas, guardião da sociedade, permite a restauração desse papel. Para a sociedade, trata-se da reviver de um passado mítico, de um tempo supostamente glorioso que, de fato, não ocorreu em nenhum setor durante os anos de ditadura. 
Entrevistadores: $\mathrm{Na}$ sua perspectiva, quais são as referências incontornáveis para compreender a História dos Militares no Brasil? Quais sugestões você daria para alguém que está iniciando os estudos sobre esta temática ou mesmo para um público mais amplo que tenha interesse em conhecer o papel dos militares e dos militarismos no país?

Claudio Beserra: Creio que a primeira sugestão é buscar conhecer as diversas interpretações sobre a atuação dos militares na política. As referências bibliográficas são muitas. Atendo-me mais à história republicana, tornam-se incontornáveis as análises de José Murilo de Carvalho, Edmundo Campos Coelho, Nelson Werneck Sodré, Alfred Stepan, João Roberto Martins Filho, Samuel Huntington e Alain Rouquié, além dos trabalhos de Eliézer Rizzo de Oliveira, Joseph Comblin, Francisco César Alves Ferraz e Paulo Ribeiro Cunha.

\section{REFERÊNCIAS}

FARIA, Fabiano Godinho. Os Militares e a Crise de 1964 - Crise Orgânica e Golpe de Classes. Curitiba: Editora Prismas, 2014.

FERREIRA, Marieta; KORNIS, Mônica (orgs.) A República na velha provincia: oligarquias e crise no estado do Rio de Janeiro (1889-1930). Rio de Janeiro: Rio Fundo, 1989.

LEMOS, Renato. Ditadura, anistia e transição política no Brasil (1964-1979). Rio de Janeiro: Consequência, 2018.

LEMOS, Renato. Benjamin Constant - vida e história. Rio de Janeiro: Topbooks, 1999.

LEMOS, Renato. Cartas da Guerra - Benjamin Constant na Campanha do Paraguai. Rio de Janeiro: IPHAN, 1999.

VASCONCELOS, Claudio Beserra. A política repressiva contra militares no Brasil após o golpe de 1964. Locus (UFJF), v. 12, p. 155-166, 2006. 
VASCONCELOS, Claudio Beserra. As análises da memória militar sobre a ditadura: balanço e possibilidades. Estudos Históricos (Rio de Janeiro), v. 22, p. 65-84, 2009.

VASCONCELOS, Claudio Beserra. Repressão a militares na ditadura pós1964. Rio de Janeiro: Arquivo Nacional, 2018.

VASCONCELOS, Claudio Beserra. Os militares e a legitimidade do regime ditatorial (1964-1968): a preservação do Legislativo. Varia História (UFMG. Impresso), v. 29, p. 333-358, 2013.

VASCONCELOS, Claudio Beserra. A repressão política aos cabos da Força Aérea Brasileira após o golpe de 19644. Revista Tempos Históricos, v. 23, p. 470-507, 2019.

VASCONCELOS, Claudio Beserra. O discurso da democracia: imprensa e hegemonia da ditadura empresarial-militar brasileira (1964-1968). Tempo e argumento, v. 11, p. 365-401, 2019.

VASCONCELOS, Claudio Beserra. A Escola Superior de Guerra e as raízes da repressão política aplicada a militares após o golpe de 1964. Revista Antiteses, v. 13, p. 278-308, 2020.

Texto recebido em 11/11/2020 e aprovado em 11/11/2020. 